\title{
M. MERLEAU-PONTY Y H. ARENDT: PENSANDO EN LA HISTORIA.
}

\author{
Ma CARMEN LÓPEZ SÁENZ \\ UNED. Madrid
}

\begin{abstract}
RESUMEN: En este trabajo pretendemos comparar y contrastar las concepciones explícitas e implícitas de la historicidad de Merleau-Ponty y Arendt. Comenzaremos trazando su filiación fenomenológica, que tiene como hilo conductor su común búsqueda del sentido de la experiencia incluso en el sinsentido, abriéndose a él desde sus situaciones y compromisos, adentrándose con el pensamiento en la fragilidad y en la contingencia que jamás excluyeron del filosofar. Mostraremos que el desarrollo merleau-pontiano de la fenomenología genética, particularmente su interpretación del concepto husserliano de la Stiftung, posibilita una concepción de la historia que podría ser aceptada por Arendt, de la misma manera que lo fue su ontología indirecta y su interrogación filosófica. Aunque su resistencia a la reversibilidad de la chair (carne) limitará la concepción arendtiana de la acción y del pensar, la interrelación de ambos pensamientos revelará la necesidad de una nueva filosofía de la historia.
\end{abstract}

PALABRAS CLAVE: fenomenología; Siftung; revolución; pensar; acción; filosofía.

\section{Merleau-Ponty and H. Arendt: Thinking in History}

ABSTRACT: In this work we intend to compare and contrast the explicit and implicit Merleau-Ponty's and Arendt's conceptions of historicity. We begin by tracing their affiliation with Phenomenology, whose common thread is the search for the meaning of experience even in the nonsense, opening to it from their situations and commitment in order to insight into the fragility and contingency that they never eliminated them from philosophizing. We will show that Merleau-ponty's development of genetic phenomenology, particularly his interpretation of the Husserlian concept of the Stiftung, it makes possible a conception of history that could be accepted by Arendt, in the same way she did with his indirect ontology and philosophical interrogation. Despite Arendt's hostility to the reversibility of the chair (flesh), which will limit the Arendtian conception of action and thinking, the interrelation of both thoughts it will reveal the need for a new philosophy of history.

KEY WORDS: phenomenology; Stiftung; revolution; thinking; action; philosophy.

\section{INFLUENCIAS FENOMENOLÓGICAS}

Merleau-Ponty (1908-1961) y H. Arendt (1906-1975) pertenecen a la misma generación; sufrieron las dos grandes guerras mundiales y expresaron sus experiencias en sus escritos. Como es sabido, la descripción de la experiencia vivida ocupa un lugar central en la fenomenología; de ahí, el interés que esta corriente suscitó tempranamente en Merleau-Ponty. El aparecer y el acontecer son, asimismo, núcleos del pensar arendtiano. Podemos considerar a Arendt fenomenóloga no sólo por ello, ni únicamente por haber sido alumna de Husserl en Friburgo (1926-1927) o por haber recibido la influencia de la fenomenología hermenéutica heideggeriana, sino, además, porque ella misma se caracterizó como tal, aunque no a la manera de Heidegger o Husserl ${ }^{1}$. Se

1 Así lo afirma S. Benhavib que sitúa las descripciones de Arendt en el terreno de la «fenomenología existencial de las experiencias políticas», The Reluctant Modernism of Hannah Arendt, Londres, Sage, 1996, p. 49. Añade que una de las metodologías empleadas 
ha subrayado como clave de su fenomenología «la adopción de un enfoque eidético a la hora de distinguir los órdenes de la vida activa ${ }^{2}$. Sin embargo, ella aseguraba que el descubrimiento más importante de Husserl fue el de la vida intencional. Interpretaba la intencionalidad en el sentido merleaupontiano de la fe perceptiva intersubjetiva ${ }^{3}$ para la que lo percibido existe con independencia del acto de percibir; esto es lo que la autora denomina «sense of realness ${ }^{4}$ para significar que la realidad es el contexto de lo que captamos, o mejor, que todo ser es del mundo. Los seres vivos «no están en el mundo, son del mundo, y esto precisamente porque son sujetos y objetos - percibiendo y siendo percibidos- al mismo tiempo $»^{5}$. Merleau-Ponty se refiere, en un sentido similar, al être-au-monde o ser abierto al mundo, porque el perceptor no es ni un sujeto absoluto, ni está dentro de un universo formado exclusivamente por objetos, sino también por vacíos entre ellos, de modo que, cuando percibe, algo se revela y algo se oculta y no lo hace únicamente ante la conciencia, sino a un inter-mundo. Como veremos, este Zwischenwelt es el campo del pensamiento arendtiano.

La primacía merleau-pontiana de la percepción se corresponde con la prioridad que Arendt otorga al aparecer, y con la máxima husserliana de «la vuelta a las cosas mismas», la cual es interpretada por ambos, principalmente, como una ruptura con el conceptualismo. Arendt la aborda como vuelta a las pequeñas cosas que nos vinculan a la existencia, a las modestas apariencias

por Arendt para recuperar el significado originario de los fenómenos es la fenomenología de Heidegger y Husserl; otra, más fragmentaria, se inspira en Benjamin (Ib., p. 172).Ver, asimismo, Young-Bruehl, E., Hannah Arendt. For Love of the World. New Haven, Yale Univ. 1982, p. 405. Siempre que no se indique lo contrario, las traducciones son nuestras.

2 Serrano de Haro, A., "Husserl en el pensamiento de H. Arendt», Investigaciones Fenomenológicas 6 (2008), pp. 299-308, p. 301. Contrariamente, Benhavid critica el «esencialismo fenomenológico» de Arendt que adscribe cada actividad a un lugar en el mundo (Op. Cit. p. 172). Nos parece necesario puntualizar la diferencia entre las esencias platónicas y las husserlianas: estas últimas son descubiertas a través de variaciones imaginativas de lo dado hasta encontrar lo invariante; habitan los hechos y funcionan como estructuras y articulaciones de los mismos. Merleau-Ponty parte de ellas para mostrar que hay esencias sensibles. (Remito al lector interesado en este asunto a mi trabajo, «La verdad de las ideas sensibles», en SAN Martín, J. y Domingo, T., La imagen del ser humano: Historia, literatura y hermenéutica. Madrid, Biblioteca Nueva, 2011, pp. 341-355). Como estos fenomenólogos, Arendt no es «esencialista» en sentido platónico; además reacciona contra toda manifestación de esencialismo en la historia, como puede verse en su singular concepción de la novedad que supone el totalitarismo y, sobre todo, rechaza la identificación entre esencia y existencia.

No obstante, a nuestro modo de ver, en la particular fenomenología arendtiana, la reflexión sobre la experiencia vivida en común pesaría más que el análisis eidético.

3 Refiriéndose a la fe perceptiva de Merleau-Ponty dice Arendt: «La apariencia siempre requiere espectadores e implica reconocimiento». ARENDT, H. (1971), The life of the Mind. New York, Harcourt, 1981, p. 46.

${ }_{4} I b .$, p. 201.

$5 \quad I b .$, p. 20. 
y a las pequeñas palabras nada aparentes ${ }^{6}$, pues, como para Merleau-Ponty, «volver a las cosas mismas» implica una radicalización del pensar sobre la base de la experiencia y el compromiso.

Se ha dicho que el pensamiento arendtiano es fenomenológico porque se ciñe a las experiencias de pensamiento y a la vida cotidiana ${ }^{7}$; Incluso se ha caracterizado la suya como una «fenomenología de la esfera pública» ${ }^{8}$, pero, sobre todo, como una antropología filosófica o una teoría política ${ }^{9}$ cuyo paso previo es la deconstrucción de las ontologías clásicas. A nuestro modo de ver, su antropología filosófica participa de la crítica fenomenológica del relativismo histórico y del anclaje del ser humano y de su acción en el mundo de la vida (Lebenswelt). En este marco, Arendt ha puesto en práctica una fenomenología de la vida activa que culmina en la acción, la praxis o energeia cuyo fin es intrínseco a ella misma. Esa praxis es política o acción común si busca los mejores fines a través del discurso (lexis) que la hace significativa. La acción política es inseparable, por tanto, de la comunicación y de la intersubjetividad en la que tanto ha profundizado la fenomenología ${ }^{10}$.

\section{Afán DE COMPRENSIÓN Y ARTICULACIÓN DEL SENTIDO}

La finalidad de Arendt es entender a los individuos y hasta su desaparición en los totalitarismos. Esta búsqueda de sentido es, como en Merleau-Ponty, indirecta, pues se guía por las huellas que dejan los conceptos sin rehuir la toma de postura ante el sinsentido. Podríamos denominarla "comprensión», subrayando que está enfocada a la construcción de un espacio común y a los acontecimientos que tienen lugar en él, los cuales no se deducen del pasado, sino que, a la inversa, son ellos los que lo esclarecen convirtiendo el acervo pretérito en un relato y originando así la historia:

La historia (history) aparece cada vez que ocurre un acontecimiento lo suficientemente importante como para iluminar su pasado. Entonces la masa

6 Arendt, H., (1948) Was ist Existenz-Philosophie? Trad. SErrano de Haro, A., "¿Qué es la filosofía de la existencia?», en (1930-1954), Ensayos de comprensión. Madrid, Caparrós, 2005 pp. 203-232, pp. 205-206.

7 Boella, L., "Phenomenology and Ontology: Hannah Arendt and Maurice MerleauPonty», en Burke, P. and Veken, V. (eds.), Merleau-Ponty in Contemporary Perspective, Netherlands, Kluwer, 1993, pp. 171-179, p. 174.

8 Moran, D., Introduction to Phenomenology, London and New York, Routledge, 2000. (Trad. cast. CAstro, F. y Lazo, P., Introducción a la fenomenología. Barcelona, Anthropos, 2011, pp. 270-300).

9 Así lo ha constatado CAmpillo, N., Hannah Arendt: lo filosófico y lo político. Valencia, PUV, 2013, p. 60.

10 La centralidad de la acción comunicativa es compartida también por Habermas, aunque él es crítico de la reducción arendtiana de la política a la praxis, aristotélicamente entendida. Cf. Habermas, J., «H. Arendt», en Perfiles filosófico-políticos. Madrid, Taurus, 1986, pp. 200-222. 
caótica de los sucesos pasados emerge como un relato (story) que puede ser contado, porque tiene un comienzo y un final ${ }^{11}$.

Un relato es la conversación interrumpida con lo que hacemos y padecemos de la que surgen «ciertos indicadores» del pasado en el presente y hacia el futuro; así entendido, «salva los asuntos de los hombres mortales de la futilidad que les es inherente» ${ }^{12}$. La relación de lo acontecido es el verdadero dominio del pasado, la expresión del pensar en la historia y la manera adecuada de comprenderla preservando la singularidad de cada periodo histórico y proporcionando orientaciones para la acción. A diferencia de la ideología que impone a las personas la lógica de las ideas, el relato prepara para entender otros acontecimientos y, en este sentido es una propedéutica del futuro. Todo esto se pierde en los totalitarismos, sean del cuño que sean.

Como ha desarrollado Ricoeur, el relato humaniza el tiempo y estructura nuestra experiencia temporal salvándola de la dispersión; contribuye a la constitución de nuestra identidad y a la comprensión de la historia. Esta referido a la acción y desarrolla el horizonte narrativo de la vida social y personal. Por consiguiente, el relato narra desplegando una potencia creadora. Se aproxima, así, a la poesía aunque, a diferencia de ella, emplea la mímesis de las acciones para subrayar los valores temporales ${ }^{13}$.

Arendt pone de relieve, asimismo, que la comprensión surgida del relato no es mera reiteración de lo acontecido, sobre todo porque «el don del “corazón comprensivo" es la facultad de imaginar» ${ }^{14}$. Ésta, como la reflexión, se distancia de lo fáctico para poder entenderlo. A diferencia de la fantasía, la imaginación se adentra en las dimensiones oscuras y densas de lo real, esas que, según Husserl, constituyen lo invariante o esencial que es descubierto realizando variaciones imaginativas sobre los hechos. En esta línea, citando a Wordsworth, Arendt afirma que la imaginación no es irracional, sino "otro nombre para... la intuición más clara, la amplitud de la mente, para la Razón en su ánimo más elevado» ${ }^{15}$. Este ánimo no existe en la racionalidad dominante que acomoda los medios a los fines instrumentales; de ahí la necesidad de recurrir a la imaginación para distanciarnos de lo dado. Resuenan los ecos de las críticas marcusianas a la razón estratégica y su reivindicación de la imaginación no domeñada. Ambos filósofos ven en ella, en efecto, la capacidad para tender puentes entre las facultades humanas, así como entre la experiencia directa, que no logra retirarse de lo experienciado, y el conocimiento "que levanta barreras artificiales» ${ }^{16}$. La comprensión consiste también en este modo de imaginación que nos orienta en el mundo. Como hemos mostrado en otro

\footnotetext{
11 Arendt, H., Essays in understanding 1930-1954. New York, Schocken, 1994, p. 319.

12 Arendt, H., (1963) On Revolution. London, Penguin Books, 1990, p. 220.

13 Ricoeur, P., (1983/5) Temps et récit. 3 vols. Paris, Seuil, 1991, vol 1, p. 12.

14 Arendt, A., Essays in understanding, p. 322.

15 Ib., p. 323.

16 Ibidem.
} 
trabajo ${ }^{17}$, la primacía que Merleau-Ponty otorga a la percepción no excluye su interés por la imaginación, que dinamiza lo sedimentado y contribuye a la creación de sentido.

Para estos filósofos, la comprensión no es, sin embargo, una metodología conducente al sentido. No consiste ni en buscar causas de los efectos ni en descifrar textos, sino en esa pretensión de articular nuestros actos con los acontecimientos, en esa "reconciliación con lo que hacemos y padecemos» ${ }^{18} \mathrm{a}$ la que hace referencia Arendt, y que no tiene nada que ver con el perdón, sino con nuestra vida. Esa reconciliación es el origen de la comprensión, mientras que de la narración de ésta resulta el sentido. En la línea de la ontología hermenéutica, Arendt considera el comprender como el modo específicamente humano de estar vivo; pues toda persona individual necesita armonizar con el mundo plural al que nació y en el que continúa viviendo. No se trata de una comprensión meramente teórica, sino que está enfocada a la construcción de un mundo común y, por tanto, a la acción.

Aunque no es un procedimiento epistemológico, la comprensión se basa en el conocimiento, está interrelacionada con él, pero lo trasciende, pues, como la precomprensión, le proporciona sentido. Al igual que Gadamer, Arendt rehabilita la pre-comprensión y el prejuicio que se saben tales, es decir, que son conscientes de anteceder a la comprensión y al juicio, respectivamente. No constituyen verdaderas determinaciones, sino horizontes de comprensión. En la pre-comprensión se fundan, por ejemplo, las ciencias y su vocabulario. Una comprensión auténtica remite al juicio y éste a los prejuicios que han precedido y orientado la búsqueda científica; ahora bien, el prejuicio sólo vale como tal cuando reconoce sus límites, es decir, cuando sabe que es un pre-juicio, no cuando se confunde con el juicio. No tiene la evidencia de éste porque no es fruto de la experiencia.

Así constituida, como vuelta hacia lo que la ha precedido y consciente de que no tiene fin, la pasión arendtiana por comprender no produce resultados definitivos; no es, por consiguiente, fabricación, sino culminación de la vita activa por la que los seres humanos que actúan pueden aceptar lo acontecido. La comprensión es la otra cara de la acción de manera análoga a lo invisible merleau-pontiano, que es el envés de lo visible. Debido a ello, la comprensión no nos abriría tanto al conocimiento como al corazón; él es el verdadero comienzo. Ese corazón comprensivo, al que hace referencia Arendt, que trasciende al yo, es, asimismo, un tema al que Merleau-Ponty alude para mostrar que el yo no asiste ni al surgimiento de una idea ni a su nacimiento, sino que los aprehende como ya nacidos: «no soy yo lo que me hace pensar como tampoco soy yo quien hace latir mi corazón» ${ }^{19}$.

Más allá del yo, el corazón es verdaderamente el que comprende el pasado, como Merleau-Ponty subraya, «en virtud del vínculo histórico que nos une

17 LóPEz, M M C., «Imaginación carnal en Merleau-Ponty», Revista de Filosofía 28, 1 (2003), pp. 157-169.

18 AREnd, H., Essays in understanding, p. 309.

19 Merleau-Ponty, M., Le Visible et l'Invisible. Paris, Gallimard, 1964, p. 275. 
a él ${ }^{20}$. Esta concepción lo acerca sin duda al pensar defendido por Arendt frente a la metafísica tradicional, pues se centra en lo que Husserl denominaba lebendige Gegenwart, en el presente viviente, que no es ni un encadenamiento de hechos ni una búsqueda de esencias. El presente así entendido está en la base de la acción en la que piensa Arendt, la acción que, a diferencia de la labor repetitiva y del trabajo productivo, es iniciativa libre que tiene su fin en sí misma; ella es la definición de la vida y de su dimensión política esencial. Esta última marca su mayor discrepancia con la praxis de Marx que, interpretada por la filósofa, convierte todo lo particular en medio. Como él, no obstante, Arendt ha sido crítica de la alienación del ser humano, aunque la escritora no sólo rechaza el economicismo marxista que reduce lo político a lo social, sino que también denuncia el menosprecio marxista por el individuo, suplido por la importancia del trabajo social y de la especie humana. Arendt se opone a esta última por considerarla una humanidad abstracta, cuando lo que realmente hay son individuos que condicionan y son condicionados por aquello con lo que se relacionan. La libertad merleau-pontiana en situación, opuesta a la libertad absoluta de Sartre, tiene un sentido similar.

También Merleau-Ponty ha reaccionado contra el determinismo marxista; sin embargo, asegura que el marxismo es «la filosofía de la historia» ${ }^{21}$, porque es una reflexión consciente de la incardinación de toda filosofía en la historia y de la praxis necesariamente transformadora. Marxismo y fenomenología ${ }^{22}$ le permiten a Merleau-Ponty abordar la historia empírica como una genealogía de la verdad que está por hacer, y cuya condición de posibilidad es que no se detenga la dialéctica ni el marxismo desemboque en cientificismo. La hiperdialéctica merleau-pontiana es una crítica de la misma que mantiene la doble dirección de la génesis, es decir, el sentido que la historia nos da junto al que nosotros le conferimos. Desde esa vigilancia activa, comprende que el mérito de Marx fue hacer del trabajo la actividad de transformación de la naturaleza y del hombre entre sí y no sólo para producir más, sino para humanizar y trascender lo fáctico con su acción simbólica. El trabajo marxista no alienado no sólo era - como piensa Arendt - un esfuerzo productivo, sino el vehículo del reconocimiento y de la emancipación. Incluso se ha dicho que, para Marx, «el trabajo es a un tiempo factor productivo y elemento expresivo ${ }^{23}$.

Merleau-Ponty comprende de este modo plural la acción en el mundo, especialmente su sentido simbólico. De ahí que no sólo reinterprete el marxismo,

20 Merleau-Ponty, M., Merleau-Ponty à la Sorbonne. Résumé de Cours 1949-1952. Grenoble, Cynara, 1988, p. 419.

${ }_{21}$ Merleau-Ponty, M., Les aventures de la dialectique. Paris, Gallimard, col. «Idées», 1991, p. 298.

${ }_{22}$ En mi trabajo, «Fenomenología y marxismo. El compromiso político de MerleauPonty», en Daimon. Revista de Filosofía, 51 (2010), pp. 103-121, he descrito minuciosamente la necesaria relación entre fenomenología y marxismo a lo largo de la obra de Merleau-Ponty.

${ }^{23}$ Honneth, A., «Lógica de la emancipación. El legado filosófico del marxismo», en Debats, $\mathrm{n}^{\circ} 37$ (1991), pp. 63-69, p. 66. 
sino que, además, abrace la pluralidad (Vielseitigkeit) interpretativa de Weber; en su opinión, éste corrige el determinismo marxista denominando «sentido» a lo que Marx llamaba «fuerzas» ${ }^{24}$; incluso hace referencia a un «marxismo weberiano ${ }^{25}$, entendido como un marxismo riguroso que ha incorporado la comprensión histórica y la elección creadora.

Desde la perspectiva del fenomenólogo francés, la comprensión es la articulación de estas múltiples perspectivas en diversas Gestaltungen de cuyo campo forma parte nuestra experiencia perceptiva y lingüística. El yo es sólo otro integrante del campo; no es él quien comprende, sino la vida que se expresa y, así, nos permite ver y dejar ver ${ }^{26}$. Es cierto que la vida incluye un enorme depósito de sentidos, aunque «la comprensión siempre es reanudada por alguien (...) pero la persona misma debe ser comprendida como institución, no como conciencia de...» ${ }^{27}$.

Al final de su vida, con su concepción de la «institución» trascenderá tanto las pretensiones de fundamentación racionalistas como las empiristas. Arendt reacciona del mismo modo contra ellas, situándose en el «entre»; en el intervalo en el que se despliega la intencionalidad que nos une al mundo.

\section{InStitución (STIFTUNG) de La historia PERSONAL y PÚblica VERSUS Fundación}

Arendt valora la fenomenología sobre todo como método que liberó a la filosofía del historicismo ${ }^{28}$. Se adhiere a su crítica de este último por considerarlo una ideología que niega la responsabilidad individual. Precisamente lo individual es lo que Merleau-Ponty preserva con su interpretación de la fundación (Stiftung) husserliana como «institución», que no es un concepto, sino «eso con lo que cuento en cada momento» ${ }^{29}$. En sus propias palabras, Husserl designó con Stiftung el conjunto de «acontecimientos de una experiencia que la dotan de dimensiones duraderas con relación a las cuales otra serie de experiencias tendrán sentido y formarán una continuación (suite) pensable o una historia $»^{30}$. "Institución» es «esta fecundidad indefinida de cada momento del tiempo que, justamente porque es singular y pasa, no podrá nunca dejar de haber sido o de ser universalmente; y más aún, la fecundidad derivada de ésta, de las operaciones de una cultura que abren una tradición, continúan valiendo tras su aparición histórica y exigen operaciones distintas e idénticas más allá

\footnotetext{
24 Merleau-Ponty, M., Les aventures de la dialectique, p. 40.

25 Ib., p. 47.

26 Merleau-Ponty, M., La Prose du Monde. Paris, Gallimard, 1969, p. 81.

27 Merleau-Ponty, M., L'institution. La passivité. Notes de Cours au Collège de France (1954-5). Paris, Belin, 2003, p. 47.

28 Arendt, H., ¿Qué es la filosofía de la existencia?, pp. 203-232, p. 206.

29 Merleau-Ponty, M., L' Institution, p. 43.

30 Ib., pp. $38,124$.
} 
de ellas mismas» ${ }^{31}$. Esas operaciones reactivan las instituciones establecidas o crean otras. Siguiendo a Husserl, «reactivar» no se reduce a explicitar lo que ya estaba implícito, sino que, además, consiste en recuperar la intención originaria total de la que lo reactivado sólo era una expresión parcial. Dicha intención es la que funda la "contemporaneidad de todas las verdades o de todas las historias» ${ }^{32}$. Si denominamos a ese origen "trascendental», debemos entender que no se opone al empírico, sino que profundiza en éste para ponernos en contacto con una historia que ha de ser explicitada sin ignorar el horizonte o campo. Por ello, Husserl aseguraba que la geometría era la Stiftung de un hecho cultural con una conciencia implícita de su historicidad ${ }^{33}$. La Stiftung es el campo intersubjetivo y socio-histórico.

El núcleo de la historicidad es, tal y como Merleau-Ponty interpreta, la Stiftung husserliana originaria de la geometría, la institución individual de lo verdadero, que está ligada a la institución pública de la tradicionalidad como sedimentación de una intención y como institución actual de un nuevo sentido a cambio del olvido de los orígenes ${ }^{34}$. Como he desarrollado en otro lugar, el fenomenólogo francés hace referencia a un olvido que conserva, a una memoria secreta que no es contraria al recuerdo explícito, sino otro modo de relación con un pasado que todavía vive ${ }^{35}$. Merleau-Ponty subraya este olvido, que encuentra en Ideas II, como precedente de la sedimentación y constitutivo de una tradición viva, que es

[...] conquista de sentido y evacuación de sentido, realización que es también destrucción. Toda institución comporta este doble aspecto, fin y comienzo, Endstiftung al mismo tiempo que Urstiftung. Esto es la sedimentación: huella (trace) del olvido, por ello mismo, apelación a un pensamiento que cuenta con él y va más lejos. La evidencia, das Erlebnis der Wahrheit, es la experiencia de esta doble relación ${ }^{36}$.

Esta relación entre el origen y el fin de la institución se produce, asimismo, en su antecedente inmediato, que es la Fundierung: «la relación de la razón y el hecho, de la eternidad y el tiempo, como la de la reflexión y lo irreflexivo ${ }^{37}$, una relación en la que el término fundado se da como explicitación del fundante y éste sólo se manifiesta a través de aquél. La refundación del sentido sedimentado en el presente es lo que hace que la institución, siendo indisociable de la historicidad, no sea mera repetición de lo que fue.

\footnotetext{
31 Merleau-Ponty, M., La Prose du Monde, p. 96.

32 Merleau-Ponty, M., L'institution, p. 42.

33 Husserl, E., [1954] Die Krisis der europäischen Wissenschaften und die transzendentale Phänomenologie, Husserliana VI. Den Haag, Martinus Nijhoff, 1976, p. 379.

34 Merleau-Ponty, M., L'institution, p. 90.

35 López SÁenz, $\mathbf{M}^{\mathrm{a}} \mathrm{C}$., «Rehabilitación de la memoria en el concepción del tiempo de Merleau-Ponty», en Ramírez, M.T., (coord.) Merleau-Ponty viviente. Barcelona, Anthropos, 2012, pp. 389-418, pp. 406 y ss.

36 Merleau-Ponty, M., L'institution, p. 99.

37 Merleau-Ponty, M., Phénoménologie de la perception, p. 451.
} 
Desde la perspectiva de Arendt, la reiteración es, asimismo, impropia de la acción; sin embargo, ella sólo comprende el olvido negativamente. Por eso, cuando glosa a René Char afirmando que hemos recibido una herencia sin testamento, la asume como carencia de tradición, «la cual selecciona y nombra, lega y preserva e indica dónde están los tesoros y cuál es su valor» ${ }^{38}$. Esta pérdida se consuma con el olvido (oblivion) ${ }^{39}$ que, para la autora, denota ausencia de rememoración; sin ésta no hay articulación ni historia que contar, sólo pensamiento ajeno a su centro, al suceso. Por el contrario, una tradición viva es la que tiene conciencia de su fundación (foundation) ${ }^{40}$, particularmente de la fundación de su autoridad ${ }^{41}$. Le interesa indagar fenomenológicamente en ella, es decir, como doble relación entre lo fundante y lo fundado o, en sus propios términos, como conversión de los inicios en fines de aquéllos que continúan viviendo.

Como Merleau-Ponty, Arendt ha reinterpretado la Stiftung husserliana como fundación libre, pero, a diferencia de él, la filósofa entiende la fundación como una brecha histórica que rompe la continuidad temporal. De ahí que utilice la palabra «foundation» para referirse a la revolución, pues la fundación no sólo es la fuente de la permanencia de la institución, sino también el principio de la libertad de fundar un nuevo comienzo, la clave de esa libertad característica de la acción con otros por la cual «algo que ha sido fundado sigue siendo obligatorio para todas las generaciones futuras ${ }^{42}$. Esta continuidad de la «obligación» es compatible con la libertad porque, a nuestro modo de ver, recupera la intención total originaria de la Stiftung fenomenológica. Debido a ello, la fundación es, para Arendt, la acción política central. Maquiavelo, a quien la filósofa considera el teórico de la fundación ${ }^{43}$, la pervirtió entendiéndola como un hacer (making) (una Italia unificada); después de él, Robespierre convirtió la fundación de la revolución Francesa en el fin que justificaba el terror. Arendt admira la revolución como fundación sin esta violencia o como «el comienzo consciente de algo nuevo» ${ }^{44}$. La revolución funda la libertad afrontando el elemento arbitrario que hay en todo comienzo ${ }^{45}$. Ahora bien, a menos que sea continuada por «la constitución de la libertad nuevamente

38 Arendt, H., (1954) Between Past and Future. Six exercises in political Thought. New York, Viking Press, 1961, p. 5. La ausencia de tradición culmina con el totalitarismo, cuya terrible originalidad se debe a que "sus acciones rompen con todas nuestras tradiciones». Arendt, H. (1953-1979), De la Historia a la acción. Trad. Birulés. Barcelona, Paidòs, 1995, p. 31.

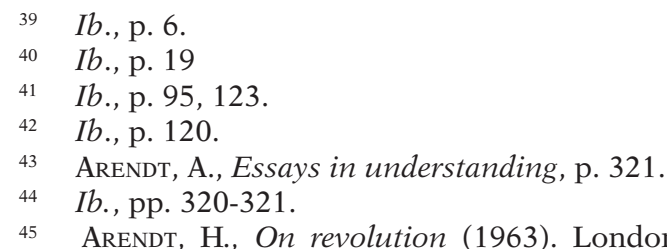
distingue la libertad de la liberación; ésta sería el fin de la rebelión. 
ganada ${ }^{46}$, esa libertad será insignificante. En este sentido, la fundación en la que piensa Arendt no es un hecho positivo y acabado, algo simplemente disponible ${ }^{47}$; constituye, en cierto modo, una llamada a la Nachstiftung o a la reinstitucionalización que lleva consigo la Stiftung merleau-pontiana, aunque la libertad nuevamente ganada a la que se refiere la filósofa no exige liberación ni emancipación, y parece asociarse a cualquier clase de acción.

Como para su coetáneo, la fundación como institución es acción y no un acto. Siguiendo a Merleau-Ponty, la institution no es un acto constituyente, pues preserva lo instituido en lo instituyente; es una acción que marca un comienzo, pero se ejerce sobre una pasividad o un depósito de sentido. Ni siquiera la Urstiftung o «institución originaria» es un acontecimiento único —como sí lo es la fundación arendtiana-, dado que incluso en esa institución primordial se produce un ininterrumpido intercambio de sentido entre lo instituyente y lo instituido. Dicho intercambio tiene lugar en un campo de presencia del que arrancan las vivencias y en el que se produce la sedimentación ${ }^{48}$ que dará sentido a las adquisiciones venideras. Todas ellas pasan a formar parte del mundo de la vida (Lebenswelt), en tanto campo ontológico en el que sujeto y objeto se instituyen en reciprocidad. En él, las revoluciones no serían fundaciones, sino reinstitucionalizaciones ${ }^{49}$, e incluso instituciones de lo no-instituido. Como la institución, la revolución crea sentidos y se nutre de los ya adquiridos, aunque sólo sea para cuestionarlos. Merleau-Ponty piensa que la verdadera revolución es crítica y auto-crítica en la historia y, como ésta, nunca puede considerarse acabada, ya que es un movimiento en el que los individuos reactivan sentidos juzgando lo que existe en nombre de lo que todavía no existe. En definitiva, «la institución no es lo contrario de la revolución: ésta es otra Stiftung» ${ }^{50}$. Incluso si derroca a la institución precedente, la revolución re-instituye. Su cometido es convertirse en institución para un futuro cuyo germen ya está en ella.

A diferencia de la constitución, "la institución en sentido fuerte es esta matriz simbólica que hace que haya apertura de un campo, un futuro según dimensiones, posibilidad de una aventura común y de una historia como conciencia ${ }^{51}$. El filósofo utiliza esta concepto de "matriz simbólica» como alternativa a la síntesis activa de la conciencia; aquélla cristaliza en torno a ciertos «núcleos inteligibles ${ }^{52}$ que configuran la «carne de la historia $»^{53}$. En ella,

46 Ibidem.

47 Cuando la autora define la autoridad buscando su etimología, destaca que proviene del verbo augere, «aumentar» y es ese aumento lo que constituye una fundación. Ib., p. 121-122.

48 Cf. Merleau-Ponty, M., Le Visible et l'Invisible. p. 275.

49 Merleau-Ponty, M., L'institution, p. 42.

50 Ibídem.

$51 \quad I b .$, p. 45.

52 Merleau-Ponty, M., Les aventures de la dialectique, p. 28. Esos núcleos inteligibles son análogos a los tipos ideales weberianos, a esa particular manera de conjugar los datos con las ideas para extraer significados a la que Merleau-Ponty dedica un buen número de páginas de esta obra.

53 Merleau-Ponty, M., Signes, Paris, Gallimard, 1960, p. 28. 
en la coexistencia, y no en la conciencia constituyente, los sujetos instituyentes son, asimismo, instituidos. Una institución no constituye significados en la conciencia, sino que ella misma «tiene significado sin mí» ${ }^{54}$. Por consiguiente, no es mera expresión del yo; supone un paso de la filosofía de las vivencias a la de nuestra Urstiftung como relación abierta e interrogativa con el pasado mirando hacia el futuro. Esa relación es fruto de nuestra libertad en situación; no es fundada por la institución; ésta sólo media entre la libertad y las determinaciones. Por el contrario, la fundación arendtiana de la libertad ligada a la acción, aristotélicamente entendida, le lleva a declarar que «el concepto de libertad ha desaparecido allí donde el concepto de historia ha reemplazado al de la política en el pensamiento moderno ${ }^{55}$.

La institución merleau-pontiana no ha heredado ese concepto moderno, sino que es la vida anónima que se ha ido sedimentando históricamente y de la que la acción sólo es una modalidad. Es la institución y no la acción la que tiene el mismo género de ser que el nacimiento, pues éste es «institución de un porvenir ${ }^{56}$, o un «nacer a». Frente al nacimiento absoluto de la acción arendtiana $^{57}$, la apertura a un futuro exige, siguiendo al fenomenólogo, una comprensión más profunda del pasado, como gestiftet en la intención fundadora $^{58}$, como instituido desde la propia situación. A pesar de todo, podemos interpretar que, en Arendt, cada nacimiento es un nuevo comienzo que re-afirma lo original del ser humano, del mismo modo que «la sucesión de las generaciones garantiza una historia que nunca puede acabar, porque es la historia de seres cuya esencia es comenzar» ${ }^{59}$. La autora manifiesta su oposición a la comprensión de la historia como cadena de hechos, pero no como ámbito de aconteceres plurales. La novedad de éstos es anulada por ese causalismo que busca en la historia la necesidad, cuando lo que realmente hay es contingencia: "la historia sin acontecimientos deviene estéril monotonía de la mismidad $»^{60}$. Que los acontecimientos sean contingentes no quiere decir que su significado lo sea. Antes bien, puesto que el sentido es compartido y resulta de la actividad del pensar, ha de ser necesario o, como dice Merleau-Ponty, toda institución de sentido es particularizante, pero también universalizante. Incluso las revoluciones son interpretadas de este modo: como reacciones del

54 Merleau-Ponty, M., L'institution, p. 37.

55 Arendt, H., (1995) Was ist Politik? Trad. cast. de Sala, R. ¿Qué es la política? Barcelona, Paidòs, 1997, p. 72.

56 Merleau-Ponty, M., L'Institution, p. 37.

57 La acción es deseo de comienzo, de natalidad o condición de haber nacido y de ser capaz de dar a luz: «La acción, con todas sus incertezas es como un recordatorio siempre presente de que los hombres, aunque han nacido para morir, no han nacido para eso, sino para comenzar algo nuevo». ARENDT, H. (1957), «Labor, trabajo, acción. Una conferencia», en De la Historia a la acción. Barcelona, Paidòs, 1995, pp. 89-107, p. 107.

58 Merleau-Ponty, M., L'institution, p. 42.

59 Arendt, A., Essays in understanding, p. 391.

$60 \quad I b .$, p. 320. Algo semejante ocurre con la razón pura que, según dice Zambrano, es pura monotonía (Zambrano, M. (1930), Horizonte del liberalismo. Madrid, Morata, 1996, p. 215. 
acontecimiento ante lo ya instituido, el cual es necesario para que haya un registro abierto o una historia ${ }^{61}$.

En ese campo en movimiento que es la historia, la verdad, según nuestros filósofos, se va haciendo en nuestras relaciones con los demás y en las respuestas a nuestras situaciones, dejando siempre un margen de sombras, que tienen un papel positivo, como la contingencia y lo sensible que nuestros filósofos rehabilitan. En el ámbito del «entre» que es el mundo en el que vivimos los seres humanos, las sombras son, como decía Fink, conceptos operativos que no fijan objetivamente y sobre los que no se reflexiona: «No es que el concepto produzca sombra, sino que ésta es su fortaleza, pues acompaña a las cosas: La fuerza iluminadora de un pensamiento se nutre de lo que permanece en la sombra del pensamiento» ${ }^{62}$. Esa brecha o "entre» es, a los ojos de Arendt, «la única región donde acaso la verdad aparecerá con el tiempo» ${ }^{63}$.

Merleau-Ponty comprende este «entre» como un gozne que une y diferencia; así es como entiende la «institución»: como intersección de lo inmediato y lo histórico, de lo personal y lo público. Renuncia a la historia que elimina el sinsentido y subsume la acción en un proceso determinista. Propone «despertar la historia salvaje (más allá de la historia "objetiva", que no se ocupa de las conciencias, y más allá de la historia como apéndice de mi aventura personal) como debate de los hombres con el pasado "en sí" o "verdadero" al que tendrían que contribuir» ${ }^{64}$. Esta concepción de la historicidad inspira su intra-ontología.

En nuestra opinión, Arendt compartiría esta actitud que se opone a la historia entendida como recopilatorio de verdades de hecho, e igualmente a su reducción a un conjunto de opiniones. Evitaría, asimismo, la confusión moderna de la historia con un proceso que presta significado universal a los sucesos eliminando justamente lo que los caracteriza: la «responsabilidad por la inscripción histórica en un mundo común y en la comprensión siempre inconclusa ${ }^{65}$. El pensar que instituye una brecha entre el pasado y el futuro es, según la filósofa, lo que hace que nos responsabilicemos del sentido del mundo y estemos dispuestos a cuestionar. Merleau-Ponty es todavía más radical, pues entiende la responsabilidad no sólo como fruto del pensar, sino como la toma de postura ante lo inaceptable ${ }^{66}$.

\section{Pensar El APARECER y dar SENTIDO A LA ACCión}

Siguiendo al fenomenólogo, pensar requiere un compromiso y una decisión; no es una acción pura. Su interpretación de lo fundado como manifestación de

\footnotetext{
61 AREndT, A., Essays in understanding, p. 40.

62 FinK, E., «Los conceptos operatorios en la fenomenología de Husserl», en: Husserl. Tercer Coloquio filosófico de Royaumont. Buenos Aires, Paidòs, 1968, pp. 192-205, p. 195.

63 Arendt, H., Between Past and Future, p. 14.

64 Merleau-Ponty, M., L'Institution, p. 179.

65 Aмiel, A., Hannah Arendt. Politique et événement. Paris, PUF, 1996, p. 14.

66 Merleau-Ponty, M., Les aventures de la dialectique, p. 7.
} 
lo fundante, así como su noción de Stiftung como conjunto de acontecimientos que apelan a una continuación, está en la línea de la revaloración arendtiana del aparecer. Con ella, Arendt deconstruye la ontología para «invertir la jerarquía metafísica que afirma la supremacía del ser sobre el aparecer» ${ }^{67}$. Vuelve, así, a las cosas mismas. Abandona todo ontologismo, pero podría adherirse a una nueva ontología indirecta como la merleau-pontiana, que sólo accede al ser lateralmente, desde la pluralidad de los entes.

En este sentido, es posible caracterizar La vida del espíritu como una nueva ontología del aparecer. La obra analiza la tensión entre el distanciamiento del mundo que supone el pensar y el aparecer del pensamiento a través del juicio. El distanciamiento caracteriza, asimismo, a la actitud fenomenológica que se inicia con la epojé. La retirada de la vida cotidiana que supone el pensar puede compararse con la epojé fenomenológica, siempre que ésta no se entienda como una simple cuestión metodológica, sino como algo connatural al pensamiento. Éste siempre interrumpe las actividades cotidianas y es interrumpido por ellas, pero el pensamiento no es ajeno al mundo; su retroceso sólo es una puesta entre paréntesis, como la epojé, que tiene por objeto volver al mundo con mayor discernimiento. El mundo que se nos manifiesta siempre es el mismo, pero, ante las mismas experiencias, como dice Arendt citando a Valéry, «a veces pienso y a veces soy» ${ }^{68}$. Seguidamente cita a Merleau-Ponty, para demostrar que pensamos en solitario, mientras que actuamos colectivamente. La pluralidad se manifiesta en ambas actividades que no se oponen, sino que se exigen, ya que la acción no tiene valor si no ha sido pensada, y el pensar requiere un lenguaje común y un depósito de significados.

Arendt distingue la necesidad de pensar de la sed de conocimiento: aquélla es una praxis que sólo se satisface pensando; incluso los pensamientos no son resultados conclusos, sino nuevos temas para pensar; por el contrario, el conocimiento es construcción de un mundo. Merleau-Ponty tampoco concibe el pensar como acumulación de datos, sino como un con-naître o un nacer al mundo con los demás, como un ex-sistere y un dar cuenta de la frágil, pero irrenunciable situación. En efecto, todo pensar nace de experiencias vividas y debe continuar ligado a ellas como únicas guías orientadoras.

El interés de Arendt por el aparecer determina, por tanto, su relación con la fenomenología, pero su identificación con el ser marca también su diferencia, pues la fenomenología de la percepción establece que cada perspectiva o situación forma parte también del aparecer. Particularmente, la fenomenología de Merleau-Ponty no absolutiza, pero tampoco prescinde ni del aparecer (Erscheinen) ni del apareciente (Erscheinende): «Ciertamente la fenomenología

67 Revault, M., «Merleau-Ponty: de la perception à l'action. Les conditions phénoménales de la politique», en Bonan, R., (éd.) Merleau-Ponty. De la perception à l'action. Aix-en-Provence, PUP, 2005, p. 113.

68 AREnd, H., The life of the Mind, p. 198. Arendt cita la traducción inglesa de Signes, cuyo original dice así: "Nous ne sommes vraiment seuls qu'à condition de ne pas le savoir, c'est cette ignorance même qui est notre solitude», p. 220. 
afectada del índice de conciencia no basta, pero lo que está más allá no es, sin embargo, sin subjetividad ${ }^{69}$.

La filósofa se apoya en uno de los estudiosos de Merleau-Ponty para oponerse a la teoría platónica de los dos mundos y afirmar que «puedo huir de la apariencia sólo dentro de la apariencia» ${ }^{70}$. Ahora bien, Arendt distingue la verdadera apariencia de la falsa, y se interesa por el aparecer de la apariencia, o sea, por el evento de lo invisible que pasa a ser visible. Esto todavía la acerca más a Merleau-Ponty, cuya concepción de la institución revela que somos miembros de un presente en el que intersectan otras dimensiones invisibles. Arendt interpreta lo invisible como el paso de la experiencia y del pensamiento a la acción, a la libertad. Ahora bien, mientras que el pensar constituye, para ella, una acción consigo misma, Merleau-Ponty lo entiende como interacción, ante todo, entre la reflexión y lo irreflexivo. El pensar, por tanto, no es ni un acto de conciencia, ni un pensamiento sobre el mundo, sino una irradiación (rayonnement) de éste en todos nosotros y de todos los seres en el mundo. Eso explica que lo invisible componga la otra cara de lo visible. En cambio, su coetánea interpreta lo invisible como la ausencia necesaria para que algo aparezca, es decir, como pensamiento. El juicio lo hace aparecer y, por ello, es la actividad política por excelencia, aunque la filósofa se pregunta si el pensamiento estará realmente destinado a ser-en-el-mundo. Merleau-Ponty, no se plantea esta cuestión, pues, para él, lo invisible no es lo que no aparece, sino otro integrante de la visibilidad. La filosofía, finalmente, no es un ejercicio solitario, pues vive de lo que se ha sedimentado en su historia y de la intención total que está en su origen. El pensar no sólo se precipita en pensamientos, sino también en impensados, que no son contrarios a lo que ya ha sido pensado; más bien, suponen nuevas reactivaciones de lo que ha quedado sedimentado, no como un conjunto de obras de museo, sino como lo que hace pensar. Análogamente, lo valioso de los grandes pensamientos, al decir de Arendt, no es su carácter de reliquia, sino el movimiento que se les imprime después, es decir, esas circunvalaciones que obligan a la mente humana a un interminable diálogo entre ella misma y la esencia de todo lo que es ${ }^{71}$.

Sin duda Arendt suscribiría la declaración merleau-pontiana de que el pensamiento comprometido "es el espíritu de la investigación ${ }^{72}$ que no puede evitar articular internamente lo que acontece. Ahora bien, él afirma que son las cosas y los acontecimientos los que nos hacen pensar, aunque posteriormente la reflexión los enriquezca; dicha re-flexión es, por otra parte, interrelación verdadera sujeto-objeto, movimiento doble de la vida interior en la exterior y a

69 Merleau-Ponty, M., Notes de Cours au Collège de France 1958-1959 et 1960-1961. Paris, Gallimard, 1996, p. 313, nota.

70 Arendt, H., The life of the Mind, p. 23. Cita a Langan, Th. Merleau-Ponty's Critique of Reason. London, New Haven, 1966, p. 93.

71 ARENDT, H., "Comprensión y política. (Las dificultades de la comprensión)», en Ensayos de comprensión, pp. 371-394, p. 392.

72 Merleau-Ponty, M., Parcours 1935-1951. Paris, Verdier, 1997, p. 113. 
la inversa. En cambio, siguiendo a Arendt, no son las cosas las que nos hacen pensar, sino el pensamiento el que toma posesión de ellas y las transforma en cosas pensadas. Este giro es característico de la prioridad tradicional del espíritu sobre el cuerpo.

Arendt conoce la filosofía de la visibilidad o de la carne (chair) de MerleauPonty, pero rechaza su reversibilidad, particularmente la que se da entre el cuerpo y el espíritu, pues, el fenomenólogo no los considera opuestos: el cuerpo está espiritualizado y el espíritu sólo tiene sentido encarnado, como el otro lado del cuerpo:

No tenemos idea de un espíritu que no esté forrado con un cuerpo, que no se establezca sobre este suelo [...], este otro lado es verdaderamente el otro lado del cuerpo, se desborda en él, se solapa con él, está escondido en él y, al mismo tiempo, tiene necesidad de él, se termina en él, se ancla en él. Hay un cuerpo del espíritu y un espíritu del cuerpo y un quiasmo entre ellos ${ }^{73}$.

Si el cuerpo es lo que incorpora al espíritu, se hace extensible a nuestro habitar con la cultura, con la lengua y con las instituciones. Por otro lado, si hay un cuerpo del espíritu, esto quiere decir que en el espíritu hay una pasividad, un descentramiento y una historicidad que también forman parte de la vida y de la búsqueda de la verdad en ella.

Aún siendo partícipe de estas ideas, Arendt cree que el propio MerleauPonty tomó conciencia de que sólo en la no identidad del cuerpo y el espíritu era posible el fenómeno mental. Le acusa de confundir el espíritu (mind) con el alma $(\operatorname{soul})^{74}$, cuando, en realidad, aquél es sin fondo y ésta se halla anclada en el cuerpo. El alma es el ámbito de las pasiones, sentimientos y emociones, «un maremágnum (welter) de acontecimientos que no son ejecutados, sino sufridos por nosotros (...) La vida del espíritu, en cambio, es actividad pura $»^{75}$. Sigue pensando, como la tradición occidental, que gracias a la razón y al control activo por parte del espíritu podemos ver:

Todo acto mental descansa en la facultad del espiritu de tener presente para sí lo que es ausente desde los sentidos. La re-presentación, el hacer presente lo que está realmente ausente, es la única donación (gift) del espíritu y, dado que toda nuestra terminología mental se basa en metáforas extraídas de la experiencia de la visión ${ }^{76}$, esta donación es denominada imaginación.

La primacía arendtiana del aparecer no rehabilita, por tanto, lo sensible, sino lo inteligible, el pensamiento. No obstante, para la fenomenología, como para Arendt, el pensar no es vacío, sino que piensa experiencias, algunas de las cuales se han convertido en esquemas conceptuales. El pensar tampoco se reduce a mera contemplación, sino que, como vimos, es condición del juicio, que, por su parte, se ocupa de lo particular de los seres socializados que toman

\footnotetext{
73 Merleau-Ponty, M. Le Visible et l'Invisible, pp. 312-3.

74 Arendt, H., The Life of the Mind, p. 33.

75 Ib., p. 72.

$76 \quad$ Ib., pp. 75-76.
} 
conciencia de que les une el pensamiento. El juicio da sentido existencial y humano al mundo, aunque nunca tiene un carácter concluyente ${ }^{77}$. La diferencia entre el discernimiento que proporciona y el pensamiento especulativo radica en que el primero es el sentido común, mientras que el segundo lo trasciende constantemente $^{78}$. Juicio y comprensión componen la actitud de subsumir lo particular en una regla general, lo que para Kant era la esencia misma del juicio cuya ausencia es calificada como «estupidez». En cambio, para Arent, el sentido común - y en esto enlaza con Gadamer-, es el sentido de lo público, el sentido político por excelencia. Tendemos a suplirlo por el razonamiento lógico, que también nos es común, aunque no tenga ninguna relación con la experiencia y, por tanto, sea incapaz de comprender nada.

El sentido común y el juicio se subordinan, en Merleau-Ponty, a la experiencia vivida y a la primacía de la percepción, la cual rehabilita la contingencia en la misma medida en que Arendt redime el aparecer. Desde el horizonte perceptivo, Merleau-Ponty cuestiona la historia, la política e incluso la filosofía. La percepción es la base del juicio y determina que la vida intersubjetiva no sea un mero apéndice de su fenomenología — una dejación de la política, diría Arendt-, sino, como en Husserl, la otra cara de la búsqueda de objetividad.

Toda la filosofía merleau-pontiana está marcada por su fenomenología de la percepción, mientras que Arendt, en la entrevista televisada, "Was bleibt? Es bleibt der Muttersprache» (1964), declaraba: «hace mucho tiempo que abandoné definitivamente la filosofía» ${ }^{79}$. Sin embargo, su interés por el sentido de la política, la vinculan, a nuestro modo de ver, a la fenomenología. De hecho, la pensadora sitúa la acción en la cima de la vida activa, pero se trata de una acción inseparable del pensamiento y del juicio. De su concepción se sigue que pensar no tiene como fin saber cómo actuar, sino que su finalidad es su propia praxis. Por ello, Arendt sólo aspira a "ganar experiencia en cómo pensar» ${ }^{80}$, no a enriquecer el pensar con la experiencia o a llevarla a la expresión de su sentido ${ }^{81}$.

Esa experiencia del pensar se asemeja a la reflexión de lo irreflexivo y a la interrogación que está en la base de la filosofía, tal y como MerleauPonty la entiende. Para él, la historia es el lugar de nuestras interrogaciones y extrañamientos ${ }^{82}$, porque tiene una indeterminación constitutiva. Del mismo modo, Arendt considera que el ejercicio interrogativo y reflexionante

\footnotetext{
77 AREnd, H., ¿Qué es política?, p. 55.
}

78 Cf. AREndt, H., Essays in understanding, p. 221.

79 La entrevista fue publicada el mismo año en el libro de Günter Gaus, Zur Person. Porträts in Frage und Antwort. Munich, Feder Verlag. Traducida el francés como "Seule demeure la langue maternelle», en el número monográfico de Esprit sobre H. Arendt, $n^{\circ} 42$, Juin 1980, pp. 19-40, p. 19.

80 ARend, H., Between Past and Future. Six exercises in political Thought, p. 14.

81 Me permito remitir al lector interesado en las potencialidades de la expresión a mi trabajo, "La expresión creadora del sentido de la experiencia», en Revista Co-herencia. Vol. 12, no 23 (2015), pp. 43-70.

82 Cf. Merleau-Ponty, M., Signes, p. 88. 
del pensamiento es «el principio del filosofar político [auténtico]»»3 . Ambos convergen en que la reflexión nunca es absoluta y en que lo originario es la pluralidad, es decir, la experiencia vivida que incita a pensar lo que acontece. Por tanto, entienden la filosofía como actividad en el mundo que, no obstante, requiere una retirada provisional de él. Tal actividad supone la crítica de la abstracción de la metafísica que les ha precedido ${ }^{84}$.

Su objetivo nunca fue saber para prever, sino para profundizar en la situación concreta que les tocó vivir, en el caso de Arendt y como ella misma decía, a pesar de sus influencias clásicas, sin tradición en la que apoyarse, pensando «sin barandillas» (ohne Geländer): «Siempre pensé que había que empezar a pensar como si nadie hubiera pensado antes y luego empezar a aprender de los demás» ${ }^{85}$. Nunca dejó de afirmar la necesidad imperiosa de ejercer el pensamiento sin seguridades mientras se vive en un mundo común y esto no era, en su opinión, una condición paradójica, sino el único modo conocido de reconciliación ${ }^{86}$.

Merleau-Ponty, siguiendo a la fenomenología, reconocía la intersubjetivididad e historicidad de los seres en el mundo, así como la tradición sedimentada y reactivada por cada individuo. Ahora bien, para ser verdaderamente común, la tradición debía realizar un movimiento doble de desapropiación y reapropiación: «ser otra para ser lo mismo, olvidar para conservar, producir para recibir, mirar hacia adelante para recibir todo el impulso del pasado» ${ }^{87}$.

En este movimiento, en el «entre» de las relaciones se desarrolla el simbolismo de la institución que enriquece a la acción:

La mayor parte de la acción se desarrolla en el punto intermedio (entredeux) entre los acontecimientos y los pensamientos puros, ni en las cosas ni en los espíritus, sino en la capa espesa de acciones simbólicas que operan más por su sentido que por su eficacia. A esta zona pertenecen los libros, las conferencias, pero también los meetings ${ }^{88}$.

El fenomenólogo denomina aquí entre-deux al inter-mundo en el que tiene cabida la profundidad de la acción, a su operatividad simbólica que, a diferencia de la coordinación estratégica, se caracteriza por la búsqueda del sentido. Esta

83 Así lo declara TAssin, E., Le trèsor perdu. Hannah Arendt-l'intelligence de l'action politique. Payot, París, 1999, p. 51.

84 Taminiaux considera que esta "paradoja» entre pertenencia y distanciamiento en Arendt está inspirada precisamente en el último Merleau-Ponty (TAminiaux, J. «La paradoxa de l'appartenence et du retrait», en Politique et pensée. Colloque Hannah Arendt. Paris, Payot, 2004, p. 128.

${ }_{85}$ Arendt, H., (1979) «On H. Arendt». Trad. cast. «Arendt sobre Arendt», en De la Historia a la acción. Barcelona, Paidòs, 1995, pp. 139-171, p. 170.

86 Ib., p. 140

87 Merleau-Ponty, M., Notes de Cours sur L'origine de la géométrie de Husserl. Barbaras, E. (dir.). PUF, Paris, 1998, p. 37. Sobre este asunto, ver mi trabajo, «Sédimentation du sens et Tradition (Überlieferung). Phénoménologie et herméneutique philosophique», Hermeneia. Journal of Hermeneutics, Art Theory and Criticism, n 12 (2012), pp. 39-62.

88 Merleau-Ponty, M., Parcours deux. 1951-1961. Lagrasse, Verdier, 2000, pp. 163-164. 
oposición a lo instrumental es la que define, asimismo, la acción, tal y como es interpretada por Arendt. El espacio «entre» es, para ambos, el mundo plural unido a la vez que diversificado. Aunque Arendt lo denomine «brecha» (gap) y Merleau-Ponty «bisagra» (charnière), los dos creen que la reflexión tiene por objeto ese lugar entre lo que ya desapareció y lo que todavía no ha aparecido: "La reflexión pone en presencia del espíritu a esas "regiones" ausentes; desde esta perspectiva la actividad del pensamiento puede ser comprendida como una lucha contra el tiempo mismo ${ }^{89}$. Ahora bien, la batalla librada por el pensamiento debe ser expresada. De ahí que Arendt declare: «hablar es una forma de acción. Es una aventura $»^{90}$, que siempre presupone la confianza en los otros.

Merleau-Ponty confía, asimismo, en lo que ha quedado sedimentado de la vida en común. Como para su coetánea, hablar y expresarse resulta tan imperioso como comprender. De hecho, filosofar es despertarse y hablar, tomar conciencia de la interrelación entre lo privado y lo público ${ }^{91}$. Arendt, por su parte, fue una gran defensora de la esfera pública, entendida como el espacio de visibilidad de los sucesos humanos libres y diversos. Ambas visiones entienden así de un nuevo modo la praxis filosófica como acción en el mundo.

Esto muestra que, aunque Arendt negara ser filósofa, los acontecimientos nos hacen introducirnos en la filosofía y, como decía Merleau-Ponty, entre ella y la historia empírica hay «identidad profunda, sin rivalidad ${ }^{92}$, justamente porque la historicidad define la historia personal e interpersonal. Asimismo, la relación entre lo propio y lo común es el centro de interés de Arendt, la cual se interroga por la discordancia entre la vida pública y la vida personal.

\section{UNA HISTORIA QUE NOS HACE AL MISMO TIEMPO QUE LA HACEMOS}

Lo que realmente rechaza Arendt no es la historia, sino el historicismo y el esencialismo en la historia. La reacción contra ellos es lo que le ayuda a comprender el totalitarismo, no como una derivación del dominio técnico o de la razón ilustrada, sino como un acontecimiento nuevo. Frente a los ensayos sociológicos y psicológicos que analizan productos concretos del totalitarismo, Arendt hace su fenomenología, es decir, describe su experiencia con objeto de encontrar sus estructuras. Lo mismo puede decirse de Merleau-Ponty, cuya filosofía de la historia va evolucionando al mismo tiempo que su valoración del marxismo y su incorporación de otras comprensiones de la historia.

89 Arendt, H., The life of the Mind, p. 206.

90 AREnd, H., Essays in Understanding, p. 23.

91 Merleau-Ponty, M., Éloge de la Philosophie et autres essais. Paris, Gallimard, 1966, pp. $72-73$.

92 Merleau-Ponty, M., Notes de Cours au Collège de France, p. 144. 
Como la acción arendtiana, la conciencia encarnada de Merleau-Ponty abre sentidos plurales de la historia en el marco de la intersubjetividad, es decir, es ese movimiento que se hace en la historia, pues ésta es fruto del cuestionamiento de lo que se ha heredado. Como consecuencia, frente a la repulsa arendtiana de la filosofía de la historia, Merleau-Ponty le da la bienvenida a la que no recorta las iniciativas, sino que les añade la obligación de «comprender otras iniciativas, de crear un camino entre mi vida y la de los los otros ${ }^{93}$.

A diferencia de su coetánea, Merleau-Ponty considera que la filosofía de la historia es la única manera de comprender la transición de la naturaleza a la cultura en la que aquélla subsiste; no obstante, se manifiesta en contra de cualquier síntesis que no sea de transición y de la concepción horizontal y progresiva del sentido. Entiende este último en su doble acepción: como significado (sensible-inteligible) y como orientación y dirección, como apertura, por tanto, consciente del non-sens. Arendt aceptaría este sentido plural que no sobrevuela las singularidades, sino que se remonta a su fuente gracias al pensar.

Así pues, aunque rechaza la filosofía de la historia que sustituye el sentido del acontecimiento por el de su inscripción en un sistema, no estaría en contra de la historicidad viviente e interesada, que su coetáneo considera condición de posibilidad de aquella otra historia documentalista. La historicidad viviente articula el sentido "disperso en la historia, esbozado en ella» ${ }^{94}$. Esta recolección del sentido se orienta a la verdad que los sujetos históricos van haciendo en su praxis ${ }^{95}$ y en su vida común, sin aceptar que la verdad sea adecuación con los hechos históricos, dado que éstos sólo pueden ser juzgados desde el punto de vista del porvenir y no desde nuestro aquí y ahora, es decir, ninguna filosofía de la historia proporciona la verdad, sino que ella misma se gesta en la historia.

Arendt no negaría esta paradoja de la verdad en situación como tarea humana y verdaderamente filosófica, pues, como declara, «la filosofía preocupada por la verdad siempre fue y probablemente siempre será un modo de docta ignorantia ${ }^{96}$. Aunque distinguió la verdad del sentido, asociando la primera con el conocimiento y la razón, y el segundo con el pensamiento ${ }^{97}$, no negó su interrelación. Ambos buscaron esta verdad convencidos de que no existía sin los otros, pero tampoco bastaba ser o estar con ellos para alcanzarla. Era necesario, además, pensar y actuar para ir haciéndola con la conciencia de que sólo aparece en la historia, pero también con el convencimiento de que si la historia quiere ser algo, debe ser historia de la verdad.

93 Merleau-Ponty, M., Signes, p. 93.

94 Merleau-Ponty, M., Résumés de Cours. Collège de France 1952-1960. Paris, Gallimard, 1968 , p. 55

${ }_{95}$ La noción de praxis de Merleau-Ponty es, como en Arendt, y en consonancia con su anti-dualismo, crítica de "la filosofía subjetivista-objetivista de la praxis» propia del bolcheviquismo (Merleau-Ponty, M., Les aventures de la dialectique, p. 130).

96 Arend, H., Essays in understanding, p. 155.

97 Arendt, H., The life of the Mind, p. 58. 
Si renunciamos a dar sentido, dejamos de contribuir a esa verdad histórica y de ejercer nuestra libertad asumiendo la situación; por ello,

Nosotros damos su sentido a la historia, pero no sin que ella nos lo proponga. La Sinn-gebung no es simplemente centrífuga, pues el sujeto de la historia no es el individuo. Hay intercambio entre la existencia generalizada y la existencia individual. Cada una recibe y da. Hay un momento en que el sentido que se dibujaba en el «se» $(\mathrm{On})$, y que no era más que un posible inconsistente amenazado por la contingencia de la historia, es reanudado por el individuo. Puede que entonces, haciéndose cargo de la historia, la conduzca... ${ }^{98}$

La génesis continuada del sentido trasciende así el dualismo de lo subjetivo y lo objetivo, pues no es ni pura construcción ni mera yuxtaposición de facta. Al igual que la acción, carece de garantías de éxito, porque la historia es la aventura del ser humano en su coexistencia social. De ahí que nuestros filósofos no confíen en las teleologías de la historia. No obstante, el fenomenólogo asegura que el descubrimiento husserliano de la Lebenswelt da comienzo a una historia operante (fungierende) en nuestras idealizaciones y, por tanto, que la «teleología» de la razón a la que se refiere Husserl se manifestaría en la confluencia de las mismas con su suelo vital. Merleau-Ponty entiende dicha «teleología» como proyecto común de la humanidad y de una filosofía que permite que cada individuo se comprenda y exprese en relación con el. La teleología es Endstiftung inmanente a la praxis institucionalizadora, como "desarrollo en zig-zag "que retoma y reactiva de otro modo lo fundado" ${ }^{99}$. No se trata, por tanto, de esa teleología criticada por Arendt como una imposición de sentido al presente, sino de otra que es movimiento de la razón en la existencia y expresión de su sentido. Así comprende Merleau-Ponty lo que Husserl denominaba «una poesía de la historia de la filosofía» ${ }^{100}$, entendida como participación en un pensamiento operante y, tal vez, como «la única objetividad para alguien que ha escrito: das Historisch an sich erste ist unsere Gegenwart... ${ }^{101}$. Lo histórico en sí primero es nuestro presente. Es preciso que sea poesía para despertar nuestro poder de crear y expresar más de lo ya dicho o vivido, para que sea un verdadero llamamiento de cada libertad a las otras ${ }^{102}$. De lo contrario, las instituciones mueren.

\footnotetext{
98 Merleau-Ponty, M., (1945) Phénoménologie de la perception. Paris, Gallimard, 1972, p. 513.

99 Merleau-Ponty, M., L'Institution, p. 99.

100 Merleau-Ponty, M., (1960) «Husserl aux limites de la phénoménologie», en Notes de Cours sur 'L'Origine de la Géometrie de Husserl. Suivi de Recherches sur la phénoménologie de Merleau-Ponty. Paris, PUF, 1998, pp. 11-94, p. 15. En efecto, Husserl se refiere a la «Dichtung der Philosophiegeschichte»(1935-6). Die Krisis der europäischen Wissenschaften und die transzendentale Phänomenologie, p. 513).

101 Merleau-Ponty, M., Résumés de Cours, p. 160. Husserl dice esto en Die Krisis, p. 382.

102 Merleau-Ponty, M., Parcours deux, p. 45.
} 
Ciertamente, Husserl consideró necesario fundar trascendentalmente el mundo de la vida en el que la teleología nos orienta, pero, según interpreta su seguidor, tal fundación era una búsqueda de la historia fundamentante (fundierend) en nosotros ${ }^{103}$, de manera que la filosofía trascendental no remitiría a la conciencia inmanente de Aufassungen, sino a nuestro ser histórico. El verdadero transcendental para Merleau-Ponty ya no sería el sujeto, sino el encuentro del pasado con la existencia actual, ese «entre» que inaugura la «historia vertical» o historia intencional operante ${ }^{104}$, la que se funda en nosotros a la vez que funda sentidos. Esta operatividad del pasado y del futuro desde el presente intersubjetivo se encuentra ya en Husserl, el cual nunca defendió una historia horizontal, sino una Stiftung como Ineinander de lo interior y lo exterior, lo propio y lo ajeno.

La prioridad de la comprensión ontológica del acontecimiento sobre el entendimiento, así como la comprensión weberiana de la acción social y su intención de reconciliar el pensamiento sobre la historia con la acción histórica influye en los dos filósofos que aquí hemos comparado, pues no sólo piensan que la pluralidad de los seres humanos es ineludible, sino que también dan libremente respuestas múltiples a lo que Merleau-Ponty denomina, «una permanente interrogación», por la que el «contacto con nuestro tiempo es una iniciación en todos los tiempos: El hombre es historiador porque es histórico, la historia no es más que la ampliación de la práctica» ${ }^{105}$.

Merleau-Ponty valora que Weber, como Husserl, «entra en el interior del hecho histórico» ${ }^{106}$ hasta encontrar la solidaridad de los diversos órdenes que intervienen en los acontecimientos. De este modo, su comprensión histórica no se reduce ni a mera asociación de circunstancias, ni a la imposición de un sentido externo. Estos dos modos de reduccionismo estudian el pasado descarnado y desprecian el presente, que es revalorizado, en cambio, por Arendt y Merleau-Ponty. Además, la historiografía objetivista no proporciona verdadero conocimiento, sino que lo mutila. Hace desaparecer la libertad «que está en el presente» ${ }^{107}$. Por ello, nuestros filósofos son tan críticos de este objetivismo como del historicismo. La historia no puede considerarse un objeto; más bien nos hace al mismo tiempo que tomamos conciencia de ella y esa conciencia histórica no es una ilusión, sino el fruto de la historia que, además, tiene efectos en la misma ${ }^{108}$. Ahora bien, en la historia no todo tiene el mismo

\footnotetext{
103 Merleau-Ponty, M., Notes de Cours au Collège de France, p. 380.

$104 \quad I b .$, p. 83.

105 Merleau-Ponty, M., Résumés de Cours, p. 50.

106 Ib., p. 49.

107 Merleau-Ponty, M., Parcours, p. 113.

108 Esta concepción dialéctica merleau-pontiana de la conciencia de la historia está resumida en Les aventures de la dialéctique, p. 48. Guarda una gran similitud no sólo con la conciencia histórica a la que reiteradamente alude Arendt, sino también con la Wirkungsgeschichtliches Bewusstsein gadameriana. Un estudio de la misma en mi contribución, «La determinación histórica en la hermenéutica de H-G. Gadamer», LóPEz SÁEnz, Ma C. y DíAz, J. M., Fenomenología e Historia. Madrid, UNED, 2003, pp. 167-183.
} 
sentido. Entendiéndola como medio de nuestros errores y también de nuestras verificaciones ${ }^{109}$, Arendt y Merleau-Ponty no sólo se opusieron al absolutismo de la verdad, sino que hicieron frente al relativismo que, llevado al extremo del «todo vale» y del «todo es posible» puede conducir al totalitarismo. MerleauPonty confió más que Arendt en la penetración de la filosofía en la historia, pero, aunque se comprometió con el marxismo y la fenomenología, nunca los consideró descripciones del porvenir. Únicamente estaba convencido de que, a diferencia del frío liberalismo, esas corrientes nos hacían más humanos, más reflexivos y solidarios con nuestro tiempo ${ }^{110}$.

\section{Conclusiones}

Con Arendt y Merleau-Ponty hemos comprendido que la ciencia de la historia no es posible, pero sí el pensar y la articulación de sus sentidos. La comprensión ontológica que ambos ponen en práctica en sus obras se aleja de la historia entendida como cuestión puramente óntica, pero se implica en otra visión de la historia que nos invita a la acción precisamente porque su sentido no está clausurado. La génesis del mismo en la Lebenswelt es testimoniada por la historicidad operante, latente ${ }^{111}$ que, siguiendo a Merleau-Ponty, forma al individuo al mismo tiempo que él o ella participa en la Stiftung.

Interpretada por Merleau-Ponty, la institución es el medio propio de la historia y de la política, pero también de la vida personal, pues su principio activo es la praxis. La historia personal y pública es institución porque es acción, pero no sólo como posicionamiento, sino principalmente como acción simbólica mediada por la historia. Esto significa que la historia instituida por las acciones se funda en esos intercambios entre la situación y la subjetividad en los que se renuevan constantemente las polaridades. De ahí que una institución no sea nada sin lo instituido y se desarrolle junto a él.

Mientras que Merleau-Ponty busca una nueva filosofía de la historia como institución para pensar las ambigüedades de la praxis, Arendt denuncia la confusión de la historia con la política, principalmente la derivación de ésta de aquélla. Como hemos visto, esto no obsta para que el modo arendtiano de entender la acción y el pensamiento sea eminentemente filosófico.

Ambos ponen de relieve el carácter relacional de la realidad, especialmente su dimensión intersubjetiva y comunicativa y el «entre» que acoge diferenciando.

109 «El error es el precio que pagamos por la verdad» (AREnd, H., The Life of Mind, p. 38).

110 López, $M^{\mathrm{a}}$ C., "Fenomenología y marxismo. El compromiso político de MerleauPonty», p. 120. Como él, Arendt expresó su rotunda desconfianza del liberalismo. ARENDT, H. «Arendt sobre Arendt», p. 167.

111 Merleau-Ponty, M., Le Visible et l'Invisible, p. 228. Me permito citar sobre este asunto mi trabajo "Intencionalidad operante en la existencia», en Sylla, B., Borges Casanova, M. (orgs.), Fenomenología VI. Intencionalidade e Cuidado. Rio de Janeiro, Via Verita, 2017, pp. 79-119 
El fenomenólogo tiene presente la acción como una de esas relaciones, pero no la absolutiza. De ahí que, para él, la historia sea el inter-mundo en el que se desarrollan las acciones humanas, mientras que para su coetánea el espacio «entre» los seres humanos sea el de la acción política: «La política, en sentido estricto, no tiene tanto que ver con los hombres como con el mundo que surge entre ellos ${ }^{112}$, y que no viene del producir, sino del actuar. Merleau-Ponty concibe el pensamiento político como «la dilucidación de una percepción histórica en la que entran en juego todos nuestros conocimientos, todas nuestras experiencias, todos nuestros valores y nuestras tesis, que son la formulación esquemática del mismo» ${ }^{113}$. Debido a ello, tiene una conciencia, más aguda si cabe, de la pluralidad y de la ambigüedad de las acciones reales, que son intencionales, y están llenas de mediaciones. Desde su perspectiva, la acción no es sólo un comienzo, sino también un compromiso y una reactivación de lo sedimentado, ya sea para continuarlo ya para criticarlo. La acción no es tampoco fuente absoluta de la libertad: tiene unas condiciones y unas consecuencias. Calificaría, sin duda, la libertad en la que piensa Arendt de descarnada, sin conquista y sin compromiso, pues, al igual que la sartreana, «nunca es un hacer [...] Su acción es un fíat mágico» ${ }^{114}$, una mera libertad de juzgar, en el caso de Sartre y quizás también en el de Arendt, que no llegó a calibrar el peso de la deliberación, la decisión, la sedimentación y el simbolismo en nuestras acciones y situaciones.

Bajo las palabras, no obstante, se esconde un común interés por la historia que hacemos y por las acciones que casi nunca pasan a la Historia. De ahí la opción de Arendt por la narración redentora de la contingencia. ¿No es un relato también el pensamiento crítico que Merleau-Ponty va desarrollando, tejiendo los pensamientos y los impensados de otras filosofías y de sus propias experiencias vividas?

Lo cierto es que ambos buscaron el sentido de la historia abriéndose al mismo desde su situación, a la vez que se adentraban reflexivamente en la fragilidad de la acción humana. El relato de la misma es el que le da sentido, según Arendt, mientras que Merleau-Ponty se inclina a pensar que es la filosofía la que concede significado a la acción, aunque ésta y las cosas se lo propongan. Esto obedece a que la institución de la acción que es la historia tiene un sentido instituyente pero también instituido. Los seres humanos amplían el significado que encuentran en los acontecimientos, de manera que el sentido ni viene absolutamente de la historia ni es completamente constituido por nosotros. Somos actores en la historia, pero también espectadores de la misma; Arendt así lo reconoce cuando distingue la acción del pensar.

Tal vez, lo más importante de sus reflexiones y lo que hoy resulta más necesario que nunca es su particular concepción fenomenológica de la historia y de la política como restauración del sentido del ser-en-el-mundo-con-otros.

\footnotetext{
112 Arendt, H., ¿Qué es la política?, pp. 117-118.

113 Merleau-Ponty, M., La Prose du Monde, p. 159.

$114 \quad I b .$, p. 287.
} 
Todo proyecto humano debe ser juzgado por su poder para reinstituir este sentido a la vez que instituye un mundo común. Todos los sentidos se ocultan y se desarrollan en la coexistencia, incluso el de la filosofía y el propio sentido histórico, el cual, siguiendo a Merleau-Ponty, es ese intercambio ambiguo que se produce en la experiencia entre la estructura de nuestra situación y la libertad de nuestra condición existencial.

Si la experiencia trascendental es, en Husserl, la experiencia dotada de sentido, la comprensión histórica, tal y como Arendt y Merleau-Ponty la entienden, sólo podría denominarse «trascendental» si no fuera una solución estática, sino el resultado de la génesis histórica de la conciencia. Exigiría, por consiguiente, una conciencia de que la Sinngebung nunca está concluida; proviene de los acontecimientos tanto como de las articulaciones narrativas y de las acciones ineludibles de los individuos que interrogan al mundo involucrándose en él. Estos pensadores reformularían, por tanto, la fenomenología transcendental, pero no tendrían reparo en aceptar la fenomenología de la Lebenswelt, de la naturaleza y la historia operantes en la experiencia: «Y la "filosofía de la historia" no sería una disciplina trascendente, sino la explicitación coherente y total de lo que significa el devenir humano, que es esencialmente filosófico» ${ }^{115}$. Teniendo en cuenta que «total» hace referencia aquí a la intención originaria, y que lo esencial del pensar sólo acontece en un inter-mundo, ¿no admitiría Arendt esta filosofía de la historia que resurge del horizonte de la pluralidad?

UNED, Madrid

Ma CARMen López SÁEnz

Facultad de Filosofía

clopez@fsof.uned.es

[Artículo aprobado para publicación en diciembre de 2016]

115 Merleau-Ponty, M., Résumés de Cours, p. 55. 